\title{
A Comparative Study of Request Speech Acts in Badrudi, Persian, and English
}

\author{
Somayyeh Daneshpazhuh ${ }^{1} \&$ Mohsen Shahrokhi ${ }^{1}$ \\ ${ }^{1}$ Department of English, Shahreza Branch, Islamic Azad University, Shahreza, Isfahan, Iran \\ Correspondence: Mohsen Shahrokhi (Ph.D.), Department of English, Shahreza Branch, Islamic Azad University, \\ Shahreza, Isfahan, Iran. Tel: 98-31-5350-2501. E-mail: shahrokhi1651@yahoo.com
}

Received: May 13, 2016 Accepted: July 12, 2016 Online Published: September 23, 2016

doi:10.5539/ijel.v6n5p82 URL: http://dx.doi.org/10.5539/ijel.v6n5p82

\begin{abstract}
This study was an attempt to delve into how requestive speech acts were realized in English, Persian, and Badrudi by EFL Persian students at the upper-intermediate level who spoke Badrudi as well. To collect the required data three versions of a Discourse Completion Test in English, Persian and Badrudi were administered to the research sample $(\mathrm{N}=40)$. The collected data was codified and analyzed with regard to social power and distance as two contextual variables and further statistical procedure was run to sustain or reject the research hypotheses. The analysis of the data revealed that the presence of power in interactions influences the request realization by the participants as there were differences among the most frequent strategies in English, Persian, and Badrudi. Moreover, with respect to the presence of social distance the comparison among request strategies in English, Persian, and Badrudi indicated the participants opt for different strategies as the most frequent strategies. The results also revealed that with the presence of power and distance direct strategies were the most frequent ones, conventionally indirect ranked second and indirect strategies were used as the least frequent strategies in English, Persian, and Badrudi.
\end{abstract}

Keywords: speech act, request, Badrudi, Persian, English, distance, power

\section{Preliminaries}

Dari language has been one of the ancient local languages of ancient Iran and it was regarded as the continuation of Patrick Pahlavi. The language drastically flourished after Islam and developed from borders of Great Khorasan to the central regions of Iran (Ajam Iraq). At the time, Ray City, which belonged to Great Khorasan, was located on the boundary between Dari Persian and Ajam Iraq's Fahlavi (Naghdi-Badi, 2006).

After occupation of Ray City by Sultan Mahmoud Ghaznavi, differences arose between Dari Persian and Ajam Iraq's Fahlavi. Also, after the defeat of Sultan Mahmoud Ghaznavi in Marv, $431 \mathrm{AH}$, the Seljuks dominated a large part of Iran and took Dari Farsi with themselves to the Ghazni and central area of Iran. Accordingly, the people of Ajam Iraq became acquainted with Dari Farsi in the fifth century (Alijanzadeh, 1993). Therefore, Dari dialects which were popular in the Ray and its surrounding areas were called "Raziaa" or "Raji". It seems that Raji dialect, i.e., the local dialect of Iran's central desert (around Kashan, Natanz, and Badrud) is a different pronunciation of Razi and is attributed to the ancient Kashan, including Badrud where it is spoken. In the center of Iran, there are about 300 dialects and accents and all of them use Persian script. The languages of ancient Kashan, Isfahan suburb, Gabri language (Yazd Zoroastrians), Naeini, Araki, ancient Natanzi, Badrudi, Khoori, Semnanie-e-Abianei, among the others, are some examples of these languages. Of course, these languages and dialects both in terms of lexicon and syntactic structure have substantial differences and similarities with Dari Persian, which can be the subject of study for researchers. Investigating Badrudi dialect — which is called "Dehi or Badi" locally-suggests that this dialect is the survivor of the ancient Pahlavi language, which fortunately has remained intact in some parts of Badrud (Alijanzadeh, 1993).

Badrudi dialect with all its characteristics, has some relationships and similarities with other Iranian languages (perhaps ancient Persian), and this indicates that the people of this territory at the time of need have given a hand to each other to save cultures and nation beside each other, though the geographical borders have separated people from each other.

According to Naghdi-Badi (2006), contemporary Badrudi dialect is much straightforward in comparison with the 
past and some of the words have been changed during the time. One of these changes which have led to the simplicity of this dialect is its emphasis on being monosyllabic, which has improved its simplicity and survival. Some examples are as follows:

Table 1. Some monosyllabic Badrudi words

\begin{tabular}{|c|c|c|c|}
\hline$/ \mathrm{Ko} /{ }^{1}: / \mathrm{koja}^{2}$ : where is ${ }^{3}$ & /Pe/: /pedær/: father & /Sav/: /si:b/: apple & /Notf/: /næ/: No \\
\hline /ei/: /yek/: one & /Bez/: /bæd/: bad & /æ/: /mæn/: I & /Næt $/: / b a ; \int e /:$ ok \\
\hline$/ \mathrm{O} \int \mathrm{k} / \mathrm{:} / \mathrm{Xp} \int \mathrm{k} / \mathrm{d}$ dry & /Mp/: /ma:dær/: Mother & /pv/: /a:b/: water & /dzen/: /zæn/: woman \\
\hline
\end{tabular}

Badrudi dialect is not comprehensible to native speakers of standard Persian due to such changes as simplification in morphemes and syntactic differences as well (Naghdi-Badi, 2006). Therefore, Badrudi dialect should be subjected to further investigations from different linguistic perspectives including pragmatics to shed more light on the similarities and differences between Badrudi and Persian as a closely related language and even other standard languages like English.

\subsection{Research Concern}

Successful communication involves not only the knowledge of grammar and text organization, but also pragmatic aspects of the target language. According to Koidke (1989), pragmatic competence is defined as the speaker's knowledge and use of rules of appropriateness and politeness, which dictate the way the speaker will comprehend and put into words speech acts in social meaning and context. One of the most important impressions of human beings is politeness. Hence, human beings cannot live and communicate with each other, if traditions of politeness are not showed in the society in which they live.

Every culture and every language has its ways of presenting respect and rigour, saving face, avoiding or reducing imposition and exercising good manners verbally and non-verbally. In this regard, as Babaie and Shahrokhi (2015) report, numerous studies have indicated that the conventions of politeness are different from one culture to another culture (e.g., see Matsumura, 2001; Golato, 2002; Nelson et al., 1996; Blum-Kulka, House, \& Kasper, 1989; Cohen \& Olshtain, 1993; DeCapua, 1998; Boxer, 1993; Einsenstein \& Bodman, 1993; Beebe \& Takahashi, 1989; Fe'lix-Brasdefer, 2004; Gass \& Houck, 1999; Kwon, 2004).

The theory of speech act (Searl, 1969) and politeness (Brown \& Levinson, 1987) are two theories affecting second language acquisition. Wolfson notes that "sociolinguistic rules are subject to considerable variation with respect to region and status" (1983, p. 66). Therefore, communities have linguistic formulas to pinpoint politeness of their members as it is important to keep the harmony in the community. However, second language learners, not familiar with such rules, may have difficulty adjusting (Wolfson, 1983). In the field, "the study of politeness have often been intertwined with studies on speech act use, especially with those that are face-threatening (FTAs) by virtue of the message conveyed” (Doğançay-Aktuna \& Kamışl1, 1996, p. 76).

According to Searl (1969, p. 18), "the speech act or acts performed in the utterance of a sentence are in general a function of the meaning of the sentence". Moreover, "the meaning of a sentence does not in all cases uniquely determine what speech act is performed in a given utterance of that sentence, for a speaker may mean more than what he actually says, but it is always in principle possible for him to say exactly what he means" (p. 18). In other words, what is said is not necessarily equal to what is meant. Pragmatics-wise, what is said is just the tip of the iceberg and the meaning is the body.

The speech act of request is considered as a face threatening act (FTA) since it requires the speaker to ask someone to do something. Considering that it has a wide application in daily communication, applying such speech act requires adequate knowledge of the target language. Therefore, in order to have a successful communication the speaker should be aware of some variables namely social power and social distance. According to Shahrokhi and Jan (2012, p. 693) "the social distance between the interlocutors is an indication of how well the speaker and the hearer know one another. Social distance has a binary value of $(+\mathrm{SD})$, where the interlocutors do not know one another well, and (-SD), where the interlocutors know one another well". The social power is defined as "the relative social dominance of one of the interlocutors on the other one" (Shahrokhi \& Jan, 2012, p. 693). When non-native speakers make requests in the target culture, they may transfer their native language request strategies into the target language and this may result in the production of inappropriate requests (Koike, 1989).

As it was mentioned, making requests in second language may be affected by First language. In standard Persian 
language, there are many different varieties such as Badrudi. Badrudi variety, as explained briefly before, is different from Standard Persian in many aspects. Making request in English, Persian, and Badrudi by Persian speakers who are native speakers of Badrudi as well as English foreign language learners has not been investigated so far. Therefore, the researchers of the current study wondered how these people use request strategies with special attention to the absence or presence of social power and distance.

According to the above mentioned problems, the present study is an attempt to explore how request speech acts are realized in English, Persian, and Badrudi variety by Persian speakers who are native speakers of Badrudi as well as English foreign language learners. On the other hand, the impact of social power and distance on marketing request is also going to be checked across the three varieties, namely Badrudi, Persian, and English.

\subsection{Research Questions}

The study addressed the following research questions:

1) To what extent do request making strategies in English, Persian, and Badrudi differ with regard to social distance?

2) To what extent do request making strategies in English, Persian, and Badrudi differ with regard to social power?

3) To what extent do request making strategies in English, Persian, and Badrudi differ with regard to social distance and power both?

\section{Method}

The present study which adopted a descriptive approach and a quantitative design employed the most common sampling in L2 research that is convenience sampling. According to (Dörnyei, 2007), in convenience sampling "participants possess certain key characteristics that are related to the purpose of the investigation" (p. 99). The main independent variables of the study were social distance and social power in Badrudi, Persian, and English whose effect was going to be checked on the dependent variable of the study, which is request speech act.

\subsection{Participants}

The present study involved a group of 40 Iranian upper intermediate EFL learners, both male and female who spoke Badrudi as one of the dialects of Persian language. They ranged between 18 and 25 in age. They were chosen non-randomly by administering a general English placement test, namely, Quick Placement Test, hereafter called QPT. It was administered to over 100 EFL Persian students who spoke Badrudi in order to make sure that they were homogeneous with regard to their English language proficiency. Based on the test scoring level chart the upper intermediate learners were selected.

\subsection{Instruments}

In order to collect the data, the researcher used different instruments in this study as follows:

\subsubsection{QPT}

To identify the proficiency level of the participants, the researchers used Quick Placement Test (QPT, version 1).

Quick placement test (QPT, version 1) was applied to know the proficiency level of the participants. This test has two sections. The first section is related to 40 questions testing situations (five questions), cloze passages-testing prepositions, grammar, pronouns, vocabulary (15 questions), and completion questions (20 questions). The second part is also composed of 20 questions; 10 questions on cloze passages, and 10 questions of completion type questions. All questions are based on multiple-choice items.

\subsubsection{Discourse Completion Task (DCT)}

The present study employed a Discourse Completion Task (DCT) which is defined as a "questionnaire containing a set of very briefly described situations designed to elicit a particular speech act" (Varghese \& Billmyer, 1996, p. 40). Ellis (1994) claims that "controlled methods such as the discourse completion questionnaire allow for large amounts of data to be collected quickly, provide information about the kinds of semantic formulas that learners use to realize different illocutionary acts, and reveal the social factors that learners think are important for speech act performance" (p. 164).

The DCT implemented in this research is a modified version adopted from Blum-Kulka et al. (1989). It consisted of 8 situations resulting in the elicitation of 8 requests and a short questionnaire about sex, age, and educational background of the participants. The situations vary according to a number of social variables such as: 1) the social distance between the speakers, and 2) the relative social dominance of the participants. Each situation was 
followed by a blank space in which the participants were asked to write a request accordingly. The items of the DCT were in English and were translated into Persian and Badrudi to prevent any interference due to misunderstanding in L2 and were checked by two Persian language teachers and a translation instructor taking into consideration that the items keep their essential meaning and that the translation was easily comprehensible. It is worth mentioning that the DCT was first presented to the students in English, two weeks later in Persian and finally two weeks later in Badrudi (the participants' mother tongue). The 8 above-mentioned situations were categorized into three categories in terms of the presence or absence of the social variables of power $(\mathrm{P})$ and distance (D) between interlocutors as follows:

Table 2. DCT categories

\begin{tabular}{llll}
\hline Combination & P & D & Situation \\
\hline A & - & + & $\begin{array}{l}\text { Getting a book from one of your lecturers (1) } \\
\text { Asking your manager to run a few errands down town (2) } \\
\text { ask your manager to borrow his car (6) } \\
\text { asking recently appointed manager at work for the money (4) }\end{array}$ \\
\hline B & + & - & $\begin{array}{l}\text { asking members of your staff to finish the project on time and stay in the office (7) } \\
\text { asking a member of your staff to type a few letters for you (8) }\end{array}$ \\
\hline C & + & + & $\begin{array}{l}\text { Asking a new trainee to answer the telephone (3) } \\
\text { asking a new trainee to use his brand new laptop for a while (5) }\end{array}$ \\
\hline
\end{tabular}

Category A comprises situations 1, 2, 6, and 4, involving interlocutors who were the less powerful requester (-P) and there was social distance between them $(+\mathrm{D})$; category B included situations 7 , and 8 in which there were familiar interlocutors (-D) with unequal power (+P). The last category, C, encompasses situations 3 , and 5 with unfamiliar interlocutors $(+D)$ and the requester of higher social power $(+\mathrm{P})$.

\subsection{Data analysis Framework}

The researchers conducted the process of analyzing the collected data through two main stages. As the initial part of the analysis, the collected data was analyzed based on a modified data analysis framework developed by Blum-Kulka et al. (1989) to classify the request strategies identified in the language varieties.

The first category of request strategies act is direct request category including the following strategies:

(A) Mood Derivable: They include "utterances in which the syntactic mood of the verb indicates illocutionary force. The prototype form is imperative. However, other forms such as infinite forms and illiptical structures express the same direct level" (Blum-Kulka et al., 1989, pp. 278-279).

(B) Performative: The illocutionary force of an utterance is the speaker's intention in producing that utterance.

The CCSARP makes a difference between Explicit Performative (for example; I am asking you to move your car), and Hedged performative. However, to suit the CCSARP coding scheme with Persian data, Explicit Performative and Hedged Performative were integrated and categorized as performative.

(C) Obligation Statement: through this strategy "the illocutionary intent is directly derivable through the semantic meaning of the locution" (Blum-Kulka et al., 1989, p. 279).

(D) Want Statement: This strategy is used when the speaker states his/her wish to be performed by the hearer.

The second category of request strategies, namely Conventional-Indirect, consists of the following strategies:

(E) Suggestory Formula: The illocutionary intent is expressed as a suggestion through Suggestory Formula.

(F) Query Preparatory: They are utterances through which the speaker monitors and checks the conditions for the viability of the request.

Finally, the Non-Conventional Indirect request makes up the third category of request strategy as follows:

(G) Hint: Hints are utterances where the illocutionary intent of the speaker is not directly derivable. The illocutionary intent of hints must be inferred by the hearer.

In addition to analyzing the data through Blum-Kulka et al. (1989) framework, the researchers classified the data according to a strategy defined by Shahrokhi (2012) as Challenging Ability.

(H) Challenging Ability: through this strategy the speaker challenged the hearer's ability in an attempt to urge him to fulfill his request. 
Table 3. Summary of the CCSARP

\begin{tabular}{lll}
\hline Level of directness & Strategy & Example \\
\hline Direct & Mood derivable & "Ask the address from this pedestrian to find the way." \\
& $\begin{array}{l}\text { Performatives } \\
\text { Obligation statements }\end{array}$ & "I would like to ask you to lend me your lecture notes." \\
& "You have to cancel your trip." \\
& Want statements & "I wanted to borrow your car for a few hours." \\
\hline Conventionally Indirect & Suggestory formula & "Why don't you ask for the address?" \\
& Query-preparatory & "Can I try your new laptop?" \\
\hline Non-conventionally Indirect & Hints & "I missed the class yesterday." \\
& Challenging Ability & "Let me see whether you can type these letters." \\
\hline
\end{tabular}

\subsection{Data Analysis Procedures}

The DCT questions were classified into three categories in terms of the absence and presence of social power and distance. Then, the DCT answers were coded in accordance with a manual, Cross-cultural Speech Act Realization Project (CCSARP-(Blum-Kulka et al., 1989)), in terms of levels of directness (direct, conventionally indirect, and non-conventionally indirect), across 8 requestive strategies (Table 3) respectively.

According to the coding procedure, the data were quantified for frequency and percentage of realization of requestive speech acts. On the other hands, the instances of request strategy production from the DCT written responses were counted and changed into percentages. Further inferential statistics were also run to check the significance of differences found.

\section{Data Analysis and Results}

The quantitative data gathered through the three DCTs as instruments of the study are tabulated below. The type and frequency of each requestive strategy employed by the participants of the study are presented so that a comprehensive comparison can be made between all the strategies across the three languages. It is worthy saying that the participants' performances in English, Persian, and Badrudi, are compared with regard to power $(\mathrm{P})$ and distance (D). The answers of the participants were categorized and tabulated as categories A (-P, + D), B (+ P, $-\mathrm{D})$, and $\mathrm{C}(+\mathrm{P},+\mathrm{D})$.

\subsection{Results of the First Research Question}

Research questions are answered according to the categories. In the first category, A (-P, + D), social power is present and social distance is absent. The participants' answers in English, Persian, and Badrudi are compared and the results are tabulated as below.

Table 4. Frequency and percentage of requestive strategies in combination A [-P; +D]

\begin{tabular}{llll}
\hline Strategy & \multicolumn{2}{c}{ F (\%) } \\
& English & Persian & Badrudi \\
\hline Mood derivable & $2(4.34 \%)$ & $4(7.69 \%)$ & $2(5 \%)$ \\
Performative & $4(9 \%)$ & $4(7.69 \%)$ & $4(10 \%)$ \\
Obligation statement & $2(4.34 \%)$ & $0(0 \%)$ & $0(0 \%)$ \\
Want statement & $4(8.69 \%)$ & $26(50 \%)$ & $16(40 \%)$ \\
Suggestory formula & $2(4.34 \%)$ & $0(0 \%)$ & $4(10 \%)$ \\
Query preparatory & $10(21.73 \%)$ & $8(15.38 \%)$ & $4(10 \%)$ \\
Hint & $12(26.09 \%)$ & $8(15.38 \%)$ & $0(0 \%)$ \\
Challenging ability & $10(21.73 \%)$ & $2(3.85 \%)$ & $10(25 \%)$ \\
\hline
\end{tabular}

The first category, A, presents four situations, namely S1 (getting a book from one of your lecturers), S2 (asking your manager to run a few errands down town), S6 (asking your manager to borrow his car), and S4 (asking recently appointed manager at work for the money). There exist a less powerful requester (-P) and there is social distance between the interlocutors $(+\mathrm{D})$. Some illustrative examples include:

Dear manager, I need your help. I have some request (English),

Lotf mikonid dar ghiaabam in kaarhaa ro anjaam bedid (Persian),

Akho do se kaar ru shar de daaron ke apia zou anjam badon. Age zahmati naha taa akho ashon bayon shoma kare min anjam bade (Badrudi). 
Regarding the directness level, the results of the analysis of the participants' speech act performance were manifold. Nearly all of the participants used conventional indirect query, direct want statement, non-conventional hint and challenging ability strategies as their preferences as far as English requestive acts were concerned. However, their requests in Persian were identified to be direct want statement, performative and, in some cases, obligation statement strategies. Still some other participants resorted to the non-conventional hint strategy. Moreover, they turned out to show preference over direct mood drivable, obligation and want statements and, in some instances, conventional indirect query and non-conventional challenging ability strategies.

According to the statistical analysis run, non-conventional hint $(26.09 \%)$, the conventional indirect query preparatory $(21.73 \%)$, and challenging ability $(21.73 \%)$ strategies are the most frequently used ones. As for the Persian and Badrudi varieties, the want statement strategy $(50 \%$ and $40 \%)$ is of the highest frequency. However, there exist no instance of requestive strategy realization such as Persian and Badrudi obligation statements and Persian suggestory formulae.

To test whether the differences between the requestive speech acts are significant, a chi-square test was conducted as presented below.

Table 5. Results of the Chi-Square test for the strategies in category A [-P; +D]

\begin{tabular}{llll}
\hline Strategy & Value & Degree of freedom & Asymp. Sig. (2-sided) \\
\hline Pearson Chi-Square & 42.873 & 14 & 0.000 \\
\hline
\end{tabular}

As Table 5 shows, the p-value is smaller than 0.05 , so there is a significant difference between the strategies at this category.

\subsection{Results of the Second Research Question}

The other category, B (+ P, -D), encompasses situations 7 (asking members of your staff to finish the project on time and stay in the office), and 8 (asking a member of your staff to type a few letters for you). It involves interlocutors who are familiar with each other (-D) and who possess unequal power $(+P)$. The table presented below manifests the frequency and percentage of the requestive strategies in category $\mathrm{B}$.

Table 6. Frequency and percentage of requestive strategies in combination B [+P; -D]

\begin{tabular}{llll}
\hline Strategy & English & Persian & B (\%) \\
& $4(16.66 \%)$ & $0(0 \%)$ & $2(10 \%)$ \\
\hline Mood derivable & $0(0 \%)$ & $0(0 \%)$ & $0(0 \%)$ \\
Performative & $8(33.33 \%)$ & $10(41.66 \%)$ & $8(40 \%)$ \\
Obligation statement & $2(8.33 \%)$ & $6(25 \%)$ & $0(0 \%)$ \\
Want statement & $0(0 \%)$ & $4(16.66 \%)$ & $4(20 \%)$ \\
Suggestory formula & $4(16.66 \%)$ & $0(0 \%)$ & $0(0 \%)$ \\
Query preparatory & $2(8.33 \%)$ & $4(16.66 \%)$ & $2(10 \%)$ \\
Hint & $4(16.66 \%)$ & $0(0 \%)$ & $4(20 \%)$ \\
Challenging ability & & & \\
\hline
\end{tabular}

According to Table 6 presented above, the participants were found to resort most to obligation statement strategy in the three languages, $(33.33 \%)$ in English, (41.66\%) in Persian, and (40\%) in Badrudi. On the other hand, the least frequent strategies $(0 \%)$ include performative and suggestory formula in English, mood derivable, performative, query and challenging ability in Persian, and performative, want statement, and query in Badrudi.

To find out a significant difference, if any, among the strategies across the three varieties (i.e., English, Persian, and Badrudi), a chi-square test was administered to the participants. The results are presented below.

Table 7. Results of the Chi-Square test for the strategies in category B

\begin{tabular}{llll}
\hline Strategy & Value & Degree of freedom & Asymp. Sig. (2-sided) \\
\hline Pearson Chi-Square & 27.280 & 12 & 0.007 \\
\hline
\end{tabular}


The p-value is smaller than 0.05 , and it shows that there is a significant difference among the strategies in Badrudi, Persian, and English.

\subsection{Results of the Third Research Question}

The last category, $\mathrm{C}(+\mathrm{P},+\mathrm{D})$ ), encompasses situations 3 (asking a new trainee to answer the telephone), and 12 (asking a new trainee to use his brand new laptop for a while) in which there are unfamiliar interlocutors $(+\mathrm{D})$, and there is a requester who has a higher social power $(+\mathrm{P})$. The following expressions are from the data.

Your laptop is great. May I use it? (English)

Baraatoon eshkaal nadaare ejaze bedid moddati baa laptope shomaa kaar konam (Persian Query)

Dale laptope nughit aade baash kaar bakerun baynon chetaia age nache bu ee aagiron (Badrudi Query)

Table 8 . Frequency and percentage of requestive strategies in category $\mathrm{C}[+\mathrm{P} ;+\mathrm{D}]$

\begin{tabular}{|c|c|c|c|}
\hline \multirow[t]{2}{*}{ Strategy } & \multicolumn{3}{|c|}{ F (\%) } \\
\hline & English & Persian & Badrudi \\
\hline Mood Derivable & $2(8.33 \%)$ & $0(0 \%)$ & $2(11.11 \%)$ \\
\hline Performative & $0(0 \%)$ & $0(0 \%)$ & $4(22.22 \%)$ \\
\hline Obligation Statement & $2(8.33 \%)$ & $4(18.18 \%)$ & $4(22.22 \%)$ \\
\hline Want Statement & $6(25 \%)$ & $14(53.84 \%)$ & $2(11.11 \%)$ \\
\hline Suggestory Formula & $0(0 \%)$ & $2(6.39 \%)$ & $0(0 \%)$ \\
\hline Query Preparatory & $8(33.33 \%)$ & $0(0 \%)$ & $4(22.22 \%)$ \\
\hline Hint & $2(8.33 \%)$ & $2(6.39 \%)$ & $0(0 \%)$ \\
\hline Challenging Ability & $4(16.66 \%)$ & $4(15.38 \%)$ & $2(11.11 \%)$ \\
\hline
\end{tabular}

Like the other two categories, this category has its own characteristics as shown in the above table. The strategies "query preparatory", "want statement", and "performative/obligation/query" are of highest frequency in English (33.33\%), Persian (53.84\%), and Badrudi (22.22\%). On the other hand Suggestory Formula and Performative in English, Query Preparatory, Mood Derivable, and Performative in Persian, and Hint and Suggestory Formula in Badrudi are the least used strategies.

A Chi-Square test was conducted in order to determine whether the requestive strategies are significantly different across the three languages involved. The result of Chi-Square test is shown below.

Table 9. Results of the Chi-Square test for the strategies in category $\mathrm{C}[+\mathrm{P} ;+\mathrm{D}]$

\begin{tabular}{llll}
\hline Strategy & Value & Degree of freedom & Asymp.Sig. (2-sided) \\
\hline Pearson Chi-Square & 34.765 & 14 & 0.002 \\
\hline
\end{tabular}

Regarding the P-value above, it can be stated that there is a significant correlation between the requestive strategies across the three varieties, English, Persian, and Badrudi.

\section{Discussion}

The results showed that in the absence of power and presence of distance hint strategy was used the most in English, and want statement was used the most both in Persian and Badrudi. Jalilafar (2009) also examined Iranian EFL learners' realization of requestive speech acts. 96 undergraduate and graduate EFL learners and 10 Australian native speakers of English were selected for the study.

The performance of participants on the DCT provided a significant evidence of the Iranian EFL learners' pragmatic aspects from direct to conventionally indirect strategies in making requests. Although the native respondents showed a more balanced production of indirect strategies, the higher proficiency EFL learners exhibited an overuse of the indirect strategies. On the other hand, the lower proficiency level caused Iranian EFL learners to produce direct request strategies excessively. According to the social variables, from perspectives of social power, the requestive performance of the EFL learners was closer to that of the Australian native speakers of English. However, they did not seem to possess sufficient sociopragmatic knowledge needed for suitable production of requests with respect to the variable of social distance.

In the presence of power and absence of distance, obligation statement was used as the most English, Persian, and Badrudi. Hendricks' study (2008) was consistent with the result of our research. He also compared request 
production in terms of opinions of situational factors and issues including relative power and social distance among Dutch learners of English, native speakers of Dutch, and native speakers of English.

In addition, the study reported similarities in selecting requestive strategies across all three groups of participants, however variations in the linguistic resources of Dutch learners of English and those of native speakers of English with respect to lexical, phraseological and syntactic revision.

In the presence of both power and distance query preparatory was used the most in English, want statement was used the most in Persian, and performative, obligation statement, and query preparatory were used the most in Badrudi. Like other studies (e.g., Taghizade, 2012) it was revealed that language can affect the strategy usage.

In another study, Taghizade (2012) investigated Iranian EFL learners' realization of requestive speech acts in comparison with British English native speakers. He investigated the requestive behavior of Iranian EFL learners from four various levels of English proficiency regarding directness, and the social variables of power as well as distance to show the Iranian EFL learners' pragmatic development in the target language learning.

In this regard, for this purpose, two materials were used; Discourse Completion Test (DCT) and Cross-cultural Speech Act Realization Project (CCSARP). Discourse Completion Test (DCT) was applied to elicit and code requestive interlanguage data from 115 Iranian EFL learners; and Cross-cultural Speech Act Realization Project (CCSARP) was used to get English baseline data from 10 British native speakers, respectively. In addition, the findings of the study showed that there was evidence of pragmatic aspects of English proficiency has developed in favor of directness and the situational variable of power. The EFL learners showed requestive performance rather different from that of native speakers in terms of strategy selection, frequency of using those strategies, and the social variable of distance.

\section{Conclusion}

This study set out to address three guiding research questions which were concerned with the effect of social power, and social distance on request making strategies in three languages. Multiple comparisons were made among languages within the three combinations of absence or presence of social power and distance.

The results showed that the presence of distance lead to greater frequency of hint strategy and want statement in English, Persian and Badrudi. On the hand, the presence of power led to the superiority of the use of obligation statement for making request in English, Persian, and Badrudi. And finally, in the presence of both power and distance, query preparatory, want statement and performative, obligation statement, and query preparatory were used the most in English, Persian, and Badrudi. Mood derivable was not of high frequency in the varieties. Overall, direct strategies overcome the other two strategies.

The present study has some implications. Successful communication and getting the massage appropriately in English needs enough knowledge about speech acts in different forms such as apologies, suggestions, compliments, requests, orders, and some others. The results of this study can contribute in enriching the EFL learners' repertoire of requestive strategies and they can help them develop their pragmatic competence. Such findings can expand the awareness of culture-specific strategies and the appropriateness of requestive strategies in different situations. Studies in pragmatic development can lead to a better understanding of how different speech acts are realized in different contexts of situations and cultures. Such studies can shed light on the effect of social variables such power and distance on the strategies which are used by the users. In the light of this study, more practice on speech acts and strategies accompanied with social variables is strongly recommended.

Other studies can consider the effect of factors such age, gender, and ethnicity on the realization of speech acts. All differences between interlocutors can change the results. Participants in different ages can be asked to take part in such studies. Male and female participants may act differently. FL learners' utterances can be compared with those of native speakers'. Longitudinal studies are suggested in order to see any progress through different kinds of teaching strategies. The participants perception and production of speech acts both orally and written can be studied. Different speech acts can be compared to each other to see whether EFL learners outperform in one or not. The performance of native, non-native, low level and high level participants can be compared with each other.

\section{References}

Achiba, M. (2003). Learning to request in a second language: A study of child interlanguage pragmatics. Clevedon, UK: Multilingual Matters.

Alijanzadeh, H. (1993). Desert Language (Aran-va-Bidgol). Shafagh publication.

Babaie, S., \& Shahrokhi, M. (2015). A Cross-cultural Study of Offering Advice Speech Acts by Iranian EFL 
Learners and English Native Speakers: Pragmatic Transfer in Focus. English Language Teaching, 8(6), 133-140. http://dx.doi.org/10.5539/elt.v8n6p133

Beebe, L. M., \& Takahashi, T. (1989). Do you have a bag? Social status and pattern variation in second language acquisition. In S. M. Gass, C. Madden, D. Preston, \& L. Selinker (Eds.), Variation in second language acquisition: Discourse and pragmatics (pp. 103-128). Clevedon: Multilingual Matters.

Biesenbach-Lucas, S. (2007). Students writing e-mails to faculty: An examination of epoliteness among native and non-native speakers of English. Language Learning and Technology, 11(2), 59-81.

Blum-Kulka, S., \& Olshtain, E. (1984). Requests and Apologies: A Cross-Cultural Study of Speech Act $\begin{array}{llll}\text { Realization Patterns (CCSARP). } & \text { Applied }\end{array}$ http://dx.doi.org/10.1093/applin/5.3.196

Blum-Kulka, S., House, J., \& Kasper, G. (1989). Investigating cross-cultural pragmatics: An introductory overview. In S. Blum-Kulka, J. House, \& G. Kasper (Eds.), Cross-cultural pragmatics: Requests and apologies. (pp. 1-34). Norwood, NJ: Ablex.

Blum-Kulka, Shoshana. (1989). Playing it safe: The role of conventionality in indirectness. In S. Blum-Kulka, J. House, \& G. Kasper (Eds.), Cross-cultural pragmatics: Requests and apologies (pp. 37-70). Norwood, NJ: Ablex.

Boxer, D. (1993). Complaints as positive strategies: What the learner needs to know. TESOL Quarterly, 27(2), 277-299. http://dx.doi.org/10.2307/3587147

Boxer, D. (2002). Nagging: The familial conflict arena. Journal of Pragmatics, 34, 49-61. http://dx.doi.org/10.1016/S0378-2166(01)00022-4

Brown, P., \& S. Levinson. (1987). Politeness: Some universals in language usage. Cambridge: Cambridge University Press.

Cohen, A. D., \& Olshtain, E. (1993). The production of speech acts by EFL learners. TESOL Quarterly, 27(1), 33-56. http://dx.doi.org/10.2307/3586950

DeCapua, A. (1998). Pragmatic transfer and cultural stereotyping. IAL (Issues in Applied Linguistics), 9(1), 21-36.

Doğançay-Aktuna, S., \& Kamışl1, S. (1996). Linguistics of power and politeness in Turkish. Proceedings of the 8th international linguistics conference (pp. 305-312). Ankara: Ankara University.

Einsenstein, M., \& Bodman, J. W. (1993). Expressing gratitude in American English.

Ellis, R. (1994). A theory of instructed second language acquisition. In N. C. Ellis (Ed.), Implicit and explicit learning of languages (pp. 79-114). San Diego, CA: Academic.

Fe'lix-Brasdefer, J. C., \& Ce'sar, B. (2004). Interlanguage refusals: Linguistic politeness and length of residence in the target community. Language Learning, 54(4), 587-653. http://dx.doi.org/10.1111/j.1467-9922.2004.00281.x

Gass, S. N., \& Houck, N. (1999). Interlanguage refusals: A cross-cultural study of Japanese-English. New York: Mouton de Gruyter.

Golato, A. (2002). German compliment responses. Journal of Pragmatics, 34(5), 547-571. http://dx.doi.org/10.1016/S0378-2166(01)00040-6

Jalilifar, A. (2009). Request Strategies: Cross-Cultural Study of Iranian EFL Learners and Australian Native Speakers. English Language Teaching, 2(1), 46-61. http://dx.doi.org/10.5539/elt.v2n1p46

Koike, D. A. (1989). Pragmatic competence and adult L2 acquisition: Speech acts in interlanguage. Modern Language Journal, 73, 279-289. http://dx.doi.org/10.1111/j.1540-4781.1989.tb06364.x

Kwon, J. (2004). Expressing refusals in Korean and in American English. Multilingua, 23(4), 339-364. http://dx.doi.org/10.1515/mult.2004.23.4.339

Matsumura, S. (2001). Learning the rules for offering advice: A quantitative approach to second language socialization. Language Learning, 51(4), 635-679. http://dx.doi.org/10.1111/0023-8333.00170

Naghdi-Badi, H. (2006). Badrud Desert Commemoration. Qum.

Nelson, G. L., Al-Batal, M., \& Echols, E. (1996). Arabic and English compliment responses: Potential for pragmatic failure. Applied Linguistics, 17(2), 411-432. http://dx.doi.org/10.1093/applin/17.4.411 
Shahrokhi, M. (2012). Perception of Dominance, Distance and Imposition in Persian Males' Request Speech ACT Strategies. Procedia-Social and Behavioral Sciences, 46, 678-685. http://dx.doi.org/10.1016/j.sbspro.2012.05.181

Shahrokhi, M., \& Jan, J. M. (2012). The Realization of Apology Strategies among Persian Males. Procedia-Social and Behavioral Sciences, 46, 692-700. http://dx.doi.org/10.1016/j.sbspro.2012.05.183

Taghizade, S. (2012). A Cross-Sectional Study of Iranian EFL Learners' Realization of Request Speech Acts. Gazimagusa, North Cyprus: Unpublished Master Thesis.

Varghese, M., \& Billmyer, K. (2000). Investigating instrument-based pragmatic variability: Effects of enhancing discourse completion tests. Applied Linguistics, 21(4), 517-552. http://dx.doi.org/10.1093/applin/21.4.517

Wolfson, N. (1983). Rules of speaking. In R. W. Shmidt (Ed.), Language and communicatoin (pp. 60-87). London and New York: Longman.

\section{Copyrights}

Copyright for this article is retained by the author(s), with first publication rights granted to the journal.

This is an open-access article distributed under the terms and conditions of the Creative Commons Attribution license (http://creativecommons.org/licenses/by/4.0/). 